\title{
A Novel Approach for Predicting the Height of Water-Conducting Fracture Zone under the High Overburden Caving Strength Based on Optimized Processes
}

\author{
Tao Hu ${ }^{1, *}$, Gongyu Hou ${ }^{1,2}, \mathrm{Su} \mathrm{Bu}^{3}$, Zhen Zhu ${ }^{4}$, Yan Wang ${ }^{5}$, Ziyi Hu ${ }^{5}$ and Zixiang $\mathrm{Li}^{1}$ \\ 1 School of Mechanics and Civil Engineering, China University of Mining \& Technology, Beijing 100083, China; \\ 108020@cumtb.edu.cn (G.H.); BQT1900605043@student.cumtb.edu.cn (Z.L.) \\ 2 School of Mining Engineering, Xinjiang Institute of Engineering, Gurumukhi 830091, China \\ 3 School of Law and Humanities, China University of Mining \& Technology, Beijing 100083, China; \\ cumtblawbusu@163.com \\ 4 School of Civil Engineering, Qingdao University of Technology, Qingdao 266033, China; \\ zhuzhen@qut.edu.cn \\ 5 Shandong Energy Group CO., LTD., Jinan 250000, China; sdenergy_wangyan@126.com (Y.W.); \\ sdeneygy_huziyi@126.com (Z.H.) \\ * Correspondence: tbp150602027@student.cumtb.edu.cn; Tel.: +86-130-5188-9511
}

Received: 13 July 2020; Accepted: 3 August 2020; Published: 6 August 2020

\begin{abstract}
The height of water-conducting fracture zones (WCFZs) is vital for the prevention of water, gas, and roof accidents in coal mines. However, its dynamic evolution law and maximum height are difficult to be obtained by traditional prediction methods, especially for conditions in which there is high overburden caving strength and a thick coal seam. Therefore, taking the 150,313 fully mechanized caving working face in Yingying Coal Mine as a background, according to the principle of optimized processes, a new predicting approach based on the Brillouin optical time-domain reflectometry (BOTDR) is proposed. Firstly, we estimated the height through empirical formula calculation, theoretical analysis, and similar model simulation tests. Secondly, we studied the optimized layout of optical cables in the overburden in detail for predicting the maximum height of the WCFZ and keeping the cables in good performance during field prediction. Thirdly, we researched and optimized the borehole parameters, optical fiber selection, and the special protection measures. Finally, we applied the aforementioned optimized outcomes in the field experiment to dynamically predict the height of the WCFZ. As a result of the field experiment, the distribution characteristics of optical fiber strain, the maximum height, and the evolution law of the WCFZ were obtained through the regular monitoring of fiber strain using BOTDR. The experiment demonstrated that its maximum height is consistent with the results studied indoors. The validation and feasibility of the approach proposed in this paper were verified via the aforementioned studies. The research in this paper has good reference value and important significance for predicting the height of the WCFZ using BOTDR in coal mines with similar geological and productive conditions.
\end{abstract}

Keywords: water-conducting fracture zone (WCFZ); Brillouin optical time-domain reflectometry (BOTDR); approach based on optimized processes; overburden; high overburden caving strength; optical fiber strain

\section{Introduction}

In China, coal is the major energy source and it accounts for about $68 \%$ of the total primary energy consumption [1]. In recent years, ensuring the safe and sustainable production of coal resources is 
a key energy problem that people have to face in China [2]. Coal safety production is an important guarantee for the stability of China's energy structure. In China, gas explosion, water inrush, and roof collapse are the three major accidents that affect the safety of coal mine production $[3,4]$. All of them are all related to the movement and deformation of overlying strata caused by coal mining, that is to say, the development of the water-conducting fracture zone (WCFZ) within the overlying strata. So, it is helpful and important to master the dynamic development law of the WCFZ and the height of the WCFZ to prevent and control the occurrence of underground accidents and ensure the safety of coal mine production.

The WCFZ occurs when the coal seam in the working face is mined out, which results in the redistribution of stress, deformation of the overlying strata, caving of the direct roof, and fracturing of the basic roof strata. With the advancing of the longwall face, there is the relaxed rock mass formed in the immediate roof (or direct roof) strata and the main roof (or basic roof) strata. The immediate roof forms the most cracked layers and creates chaotic rubble rocks in the goaf; the main roof consists of strongly fractured rocks that retain the form of geometrical continuity in the goaf; the overlying rock layers above the two parts of the relaxed rock mass can be described as a disturbed rock mass, and as a result of the deflection of the layers during coal seam mining, cracks are also formed. The frequency of these cracks is less frequent than in a relaxed rock mass, and they do not lose their geometrical continuity during settlement. This process takes much longer and is delayed compared to the layers of the relaxed roof. The phases of behavior of the rock mass follow one another and are connected with the increasing run along the strike of the longwall face [5]. So, the entire overlying strata affected by mining can be divided into three zones according to the movement of the rock strata and degree of damage, i.e., the caving zone (I), fracture zone (II), and bending zone (III) from the bottom to the top [6]. The caved zone and fractured zone are collectively named the water-conducting fracture zone (WCFZ), which is also known as the "upper two zones", as illustrated in Figure 1.

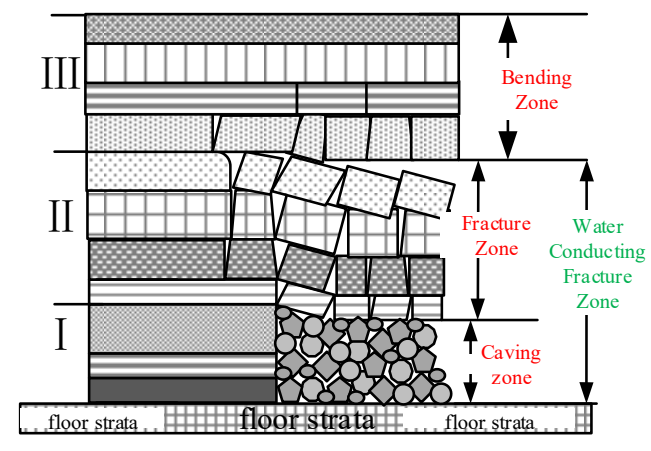

Figure 1. "Three-zone" morphological distribution in the strata overlying a mined coal seam.

Nowadays, there are some 5 categories of the methods for the prediction of the height of the WCFZ—-that is, similar model experiment [7], numerical simulation [8], empirical formula [9] and theoretical analysis [10], engineering analogy [11], and field testing experiment [12]. The field test is still considered to be the most effective and practical method due to the various geological conditions underground in various coal mines. There are several traditional methods that can be utilized for field prediction of the height of the WCFZ, such as drilling fluid loss measurement on the Earth's surface [13], water leakage through boreholes underground [14], the electric resistivity method (ERM) [15], deep multi-point displacement detector through a borehole [16], microseismic monitoring [17], borehole photographing and borehole TV cameras [18], borehole core analysis [19], etc. These traditional methods have made great contribution to the understanding of the WCFZ in coal mines. However, these methods belong to the point monitoring technology with respect to space and time sequence, the quantitative and accurate degree are not high, and they cannot dynamically reflect the evolution process of the height of the WCFZ. The measured results rely too much on the subjective judgment of testers, so they have certain fatal defects and limitations applied in reality production. 
With the rapid development of optical fiber sensing technology, as distributed optical fiber sensing (DOFS) technology has the advantages of long distance, large range, and easy networking, it provides a promising means for deformation monitoring of overlying strata. Due to optical fiber's intrinsic properties of fine, soft, high precision, corrosion resistance, anti-electromagnetic interference, explosion-proof [20], etc., it has been widely used in various aspects of coal mine safety monitoring in a mature way [21-23]. Unfortunately, there are only a few studies reported for the prediction of WCFZ based on DOFS. Zhang [24] carried out a Brillouin optical time-domain reflectometry (BOTDR) field test on the height of the WCFZ caused by $4 \mathrm{~m}$ coal seam mining by using advanced drilling in a roadway; Liu [25] made use of steel strand optical cables and fixed-point optical cables to monitor the height of the WCFZ caused by mining a $2.4 \mathrm{~m}$ coal seam via vertical borehole using BOTDR in a roadway; Piao [26] carried out the measurement of overburden separation caused by the mining of a $1.9 \mathrm{~m}$ thick coal seam based on BOTDA via the vertical borehole drilled from the ground to the underground. Cheng [27] conducted a BOTDR-based field test of the height of the WCFZ caused by the $3.11 \mathrm{~m}$ coal seam mined; in his tests, Glass fiber reinforced sensing optical cable (GFRS) and three other fixed-point cables were used, which were buried in vertical boreholes from the ground to the goaf underground; for the mining of thick coal seams in soil-rock composite structure overburdens, only Liu [28,29] conducted field tests based on BOTDR adopting three types of cables-Metal kieso sensing optical cable (MKS), Glass fiber reinforced sensing optical cable (GFRS), and fixed-point optical cables-which were embedded vertically into boreholes from the surface to the goaf underground, too.

In summary, the aforementioned tests were performed under the conditions of thin coal seam and soil-rock composite structure overburdens respectively after all, which resulted in the lower mining stress and the lower caving strength of the overburden. These are obviously inconsistent with the current prevailing mining conditions of a thick coal seam, large mining height, high in-situ stress, high mining stress, and strong overburden collapse strength in China nowadays; secondly, from their experiments, no matter whether it was above ground or underground, the layout of drilling holes and the setting of drilling parameters mainly rely on personal subjective judgment, which is more arbitrary and random, making it is easy to cause a waste of manpower, material, time, and so on. Thirdly, the location of the ground drilling cannot be arbitrarily ascertained; many facilities need to be avoided such as villages, farmlands, reservoirs etc. So, it generates a question of whether the aforementioned heights were the maximum height of the WCFZ on Earth, which needs to be discussed furthermore; the most important thing is that under the high mining stress and the ultra-high strength of overburden collapse nowadays, how can the optical cables smoothly monitor the maximum height and dynamic evolution process of the WCFZ without being damaged? So, it is urgent and pressing for us to further study and explore a scientific state-of-the art approach to solve these problems as soon as possible for the safety of coal mine production.

Since the field prediction of the height of the WCFZ is a large expense project, for preventing the prediction failure, the optimized processes should be studied and utilized. In view of the variously successful predictions in many mature fields, these are helpful for us to predict the height of the WCFZ. For example, Maciej Pawełczyk et al. [30] performed traditional and modern methods for the prediction of gas turbine operating characteristics and its potential failures. Agnieszka Chudzik et al. [31] carried out a study on the impact of a combined load of a radial cylindrical roller bearing for its predicted fatigue life using the basic package of the ANSYS program. David Vališ et al. [32] proposed new methods to model long-range mine belt degradation and a prognosis for system failure occurrence adopting the mathematical modeling of real diagnostic data with the use of selected stochastic processes, including types of Wiener process and the Ornstein-Uhlenbeck process. Kozłowski E. et al. [33] recommended a multidimensional scaling method to identify the factors influencing the reliability of deep wells in the water distribution systems (WDS). Bo Sun et al. [34] took the cantilever beam structure as a case study for developing an innovative time-variant reliability analysis method based on non-probabilistic theory for structures. So, according to the processes that range from easy to difficult, from simple to 
complex, from costing the least to the most, etc., a new approach based on optimized processes to field predict the maximum height of a WCFZ is put forward in this paper.

In this paper, under the approach based on optimized processes and on the 150,313 working face of Yinying Coal Mine, the optical cables were embedded in the overlying formation via polyvinyl chloride (PVC) tubes along a borehole prior to mining. The borehole was drilled from the roof of the roadway up to the overlying strata. BOTDR was used to monitor the optical fiber strain distribution and its variation as the working face advances. In the experiment, the optical cable withstood the influence of strong overburden caving caused by a large mining height. The strain distribution characteristics of the BOTDR optical fiber in the whole period were obtained, and the dynamic development law and the maximum height of the WCFZ were obtained. The new state-of-the art approach based on the optimized processes proposed in this paper is of great significance for the prediction of the height of WCFZ in coal mines with similar geological and productive conditions.

\section{BOTDR Distributed Optical Fiber Sensing Technology}

BOTDR technology uses the principle of Brillouin time-domain reflection. When incident light is injected into one end of the optical fiber, the interaction between the light wave and phonon incident on the optical fiber produces Brillouin back-scattering light (BBL) with a Lorentzian-shaped power spectrum [35] due to the Doppler effect, which propagates in the direction opposite to the incident light wave. The frequency of the BBL is related to the axial strain of the fiber and the temperature of the fiber. When the axial strain and temperature of the fiber change, the Brillouin frequency shift $v_{b}$ occurs in the BBL, which has a good linear relationship with the strain $\varepsilon$ and the temperature change $T$ of the fiber [36], as shown in Equation (1):

$$
v_{B}(\varepsilon, T)=v_{B}\left(\varepsilon_{0}, T_{0}\right)+\frac{d v_{B}(\varepsilon)}{d \varepsilon} \cdot\left(\varepsilon-\varepsilon_{0}\right)+\frac{d v_{B}(T)}{d T} \cdot\left(T-T_{0}\right),
$$

where $\varepsilon_{0}$ is the initial fiber strain, $T_{0}$ is the initial temperature, $\varepsilon$ is the fiber strain, $T$ is the fiber temperature, $d v_{B}(\varepsilon) / d \varepsilon$ is the fiber strain coefficient, and $d v_{B}(T) / d T$ is the fiber temperature coefficient.

As the temperature has much less effect on the Brillouin frequency shift than the strain, the temperature change can be ignored or discounted based on the temperature compensation [37]. The relationship between Brillouin frequency shift and strain can be expressed [38] by Equation (2).

$$
v_{B}(\varepsilon)=v_{B}(0)+\frac{d v_{B}(\varepsilon)}{d \varepsilon}
$$

As BOTDR uses optical time domain reflectometry (OTDR) technology to monitor the distribution of the BBL spectrum along the optical fiber, as shown in Figure 2, pulse light is transmitted at one end of the optical fiber, and BOTDR receives BBL at the same end of the optical fiber through time-domain analysis. Therefore, the distance $z$ from the position where the pulse light is emitted to the position where the BBL is generated can be determined using the following Equation (3).

$$
z=\frac{c \cdot T}{2 n}
$$

where $c$ is the light speed in vacuum, $T$ is the flight time of probe pulse, and $n$ is the refractive index of the optical fiber. 


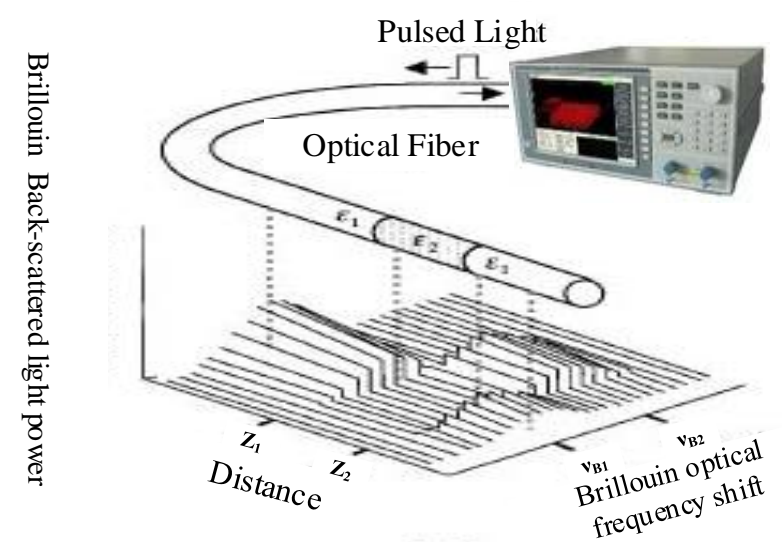

Figure 2. Diagram of Brillouin optical time-domain reflectometry (BOTDR) fiber strain monitoring principle.

According to the spectral width, a large number of power distributions of BBL with different frequencies can be obtained by slightly changing the incident light, so that the spectrum of BBL at any position along the fiber can be obtained from these wave patterns.

When the optical fiber is laid on the surface or buried in the interior of geological body, the deformation of the monitored structure will cause corresponding strain changes in the optical fiber. According to Formulas (1)-(3), the measurement and location of Brillouin frequency shift at each point on the fiber can be completed. Finally, according to the linear relationship between Brillouin frequency shift and strain, the axial strain distribution of the fiber can be obtained.

\section{Design the Field Experiment Scheme Based on BOTDR}

\subsection{Overview of the 150,313 Working Face for Field Test of the Maximum Height of WCFZ}

Yinying Coal Mine is located in the northeast of Qinshui Coal field, Yangquan city, Shanxi Province, China. The mining coal seam is 15 coal of Taiyuan Formation in Paleozoic era with an average thicknesses of $7.31 \mathrm{~m}$. Its geological conditions are relatively simple at a depth of approximately $400 \mathrm{~m}$. The attitude of the strata is nearly horizontal. The top and bottom strata properties are shown in Figure 3. The direct roof of the $15 \mathrm{coal}$ is carbonaceous mudstone of $0.92 \mathrm{~m}$ thickness, while the basic roof is $\mathrm{K}_{2}$ limestone with a thickness of $12.5 \mathrm{~m}$. The overburden is mainly composed of the Paleozoic Carboniferous Taiyuan Formation and the Permian Shanxi formation. The Mesozoic strata are weathered and eroded, and the Quaternary loess sedimentary layer appears slightly.

The 150,313 working face adopted the long wall fully mechanized caving technology for coal mining, with a mining thickness of $3.0 \mathrm{~m}$ and a caving height of $4.31 \mathrm{~m}$. The roof management was the total caving method. The strike length of the working face was $990 \mathrm{~m}$, and the inclination length is $228 \mathrm{~m}$. The west side of the air-intake gateroad of the 150,313 working face was the unmined 150,315 working face. The east side of the air-return gateroad was gob of the 150,311 working face. The air-intake gateroad was supported by rock bolts, anchor cables, steel wire meshes, and W steel belts, and in front of the working face of the air inlet lane, a $20 \mathrm{~m}$ hydraulic advance supporting-bracket was used. It can be seen that the overlying strata over 15 coal mainly comprise hard, thick limestone, and sandy stones. It also can be inferred that the overburden collapse strength would be strong and violent due to the large caving space when the 15 coal of $7.31 \mathrm{~m}$ thickness was mined out, as shown in Figure 3. 


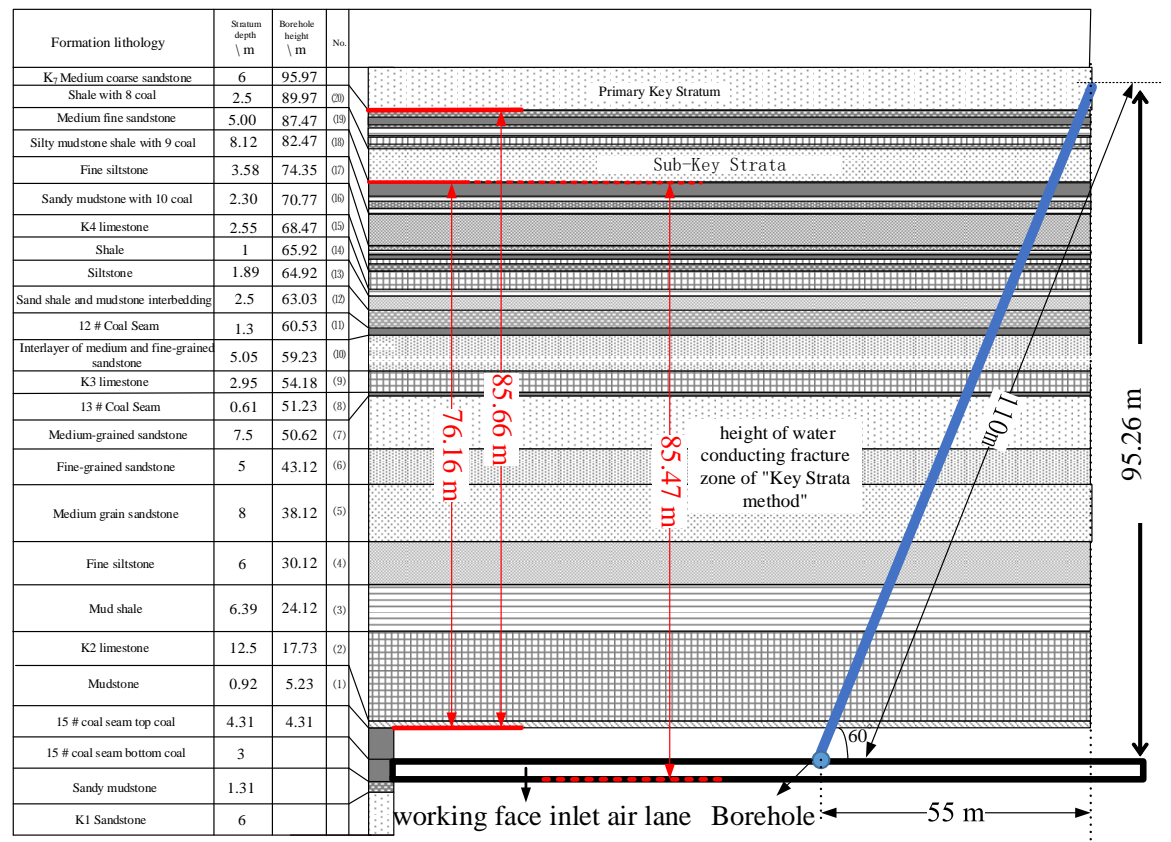

Figure 3. Stratum histogram of working face 150,313.

\subsection{Introduction of Previous Optical Fiber Strain Monitoring of Rock Movement in Early Stage}

In the beginning of 2019, in order to monitor the strata movement and deformation of the overburden in the working face using BOTDR, an optical fiber strain observation borehole was designed $300 \mathrm{~m}$ away from the open cut. Its occurrence was vertical to the working face trend with an inclination of $45^{\circ}$ and a borehole length of $70 \mathrm{~m}$. The PVC pipes that were bounded on the opposite side respectively with $5 \mathrm{~mm}$ steel strand (SS) cables and $2 \mathrm{~m}$ Fixed-Point (FP) cables were deployed into the borehole; the borehole was grouted and consolidated. Due to the influence of intense rock collapse and rock failure, one end of the FP optical cables was broken when the working face was close to the borehole, and the data were only tested from the other end of the SS optical cables. After the working face passed the borehole on 7 September, the SS optical cables were broken at the bottom of the borehole on the morning of 10 September, and the SS optical cables were broken near the orifice on the afternoon of 10 September. The acquisition time of effective data of strain change is only 3 days, and only the strain within $9 \mathrm{~m}$ of the working face passed through the borehole [12], as shown in Figure 4 . The acquisition time window of effective change data was too small to dynamically characterize the evolution process of the height of the WCFZ; only the movement rule of overburden before the fiber broke was obtained.

According to the strain monitoring results in the previous drilling, under the condition of the overburden of the 150,313 working face in Yinying Coal Mine, the fracture movement of rock strata was relatively strong and intense. The collapse strength of the thick and hard overlying strata were extreme terrific, which caused great damage to the drilling hole and optical cables; especially, the fixed-point optical cables could neither reflect the movement and deformation of the rock strata nor withstand the intensive strength of overburden collapse. Although it was demonstrated that the $5 \mathrm{~mm}$ SS cables had better capacity of resistance to the damage of the overburden caving, it could not survive during the whole monitoring process without special protection countermeasures under the violent and large strength of overburden collapse in the 150,313 working face. 


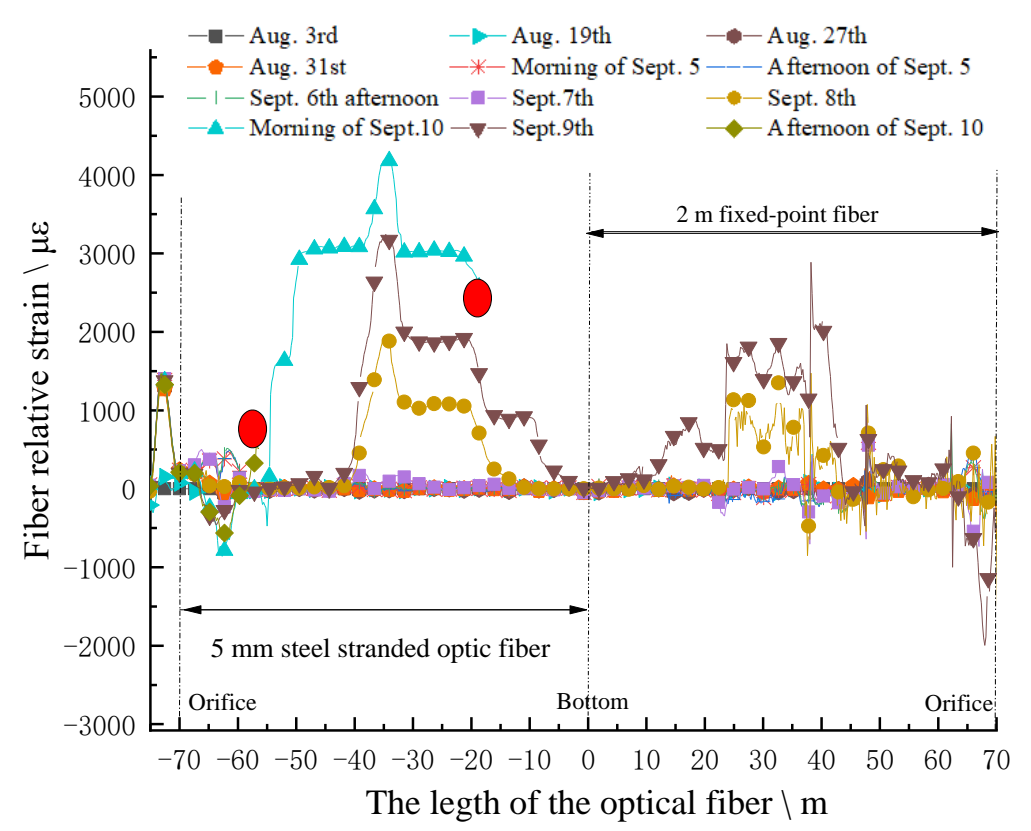

Figure 4. Fiber strain in the strata movement monitoring borehole.

Therefore, in order to successfully complete the field prediction of the height of the WCFZ and moderate the failure effects of the violently intensified collapse and movement of the overburden, it is necessary to develop a new approach that optimizes the processes: optimizing the drilling occurrence design, optimizing the protection measures to the damage of the overburden caving, and perfecting the selection of the appropriate type of optical cables to avoid the direct damage and so on.

\subsection{Optimized Processes for Predicting the Height of WCFZ}

On the premise of saving time and capital cost, in order to successfully predict the maximum height of the WCFZ under the condition of thick coal seam caving mining with high strength of overburden collapse, a new approach with universal significance is put forward in this paper based on the scientific process. Firstly, it involves carrying out indoor research to estimate the maximum height. Secondly, it requires studying and analyzing the caving angle and collapse line of overburden caused by mining. Thirdly, conclusions are drawn regarding the drilling parameters according to the estimated height and caving angle. Fourthly, it involves drilling a borehole in the roof of the air-intake gateroad upwards to the overburden, ensuring that the borehole should be as close as possible to the collapse line, and the dip angle of the borehole should be a little bit smaller than the caving angle. Finally, it involves binding the selected optical cable to the PVC pipes, sending the PVC pipes into the drilling borehole, and grouting the borehole to couple the optical cable with overburden. The most important step is that it must be implemented to carry out borehole protection measures during the field test of BOTDR in time.

According to the new aforementioned process approach, a new field prediction is going to drill a new borehole that is $550 \mathrm{~m}$ away from the open cut; it is planned to predict the maximum height of the WCFZ of the 150,313 working face. The validation and the feasibility of the new approach with optimized process are going to be verified in the experiment.

\subsection{Estimation of the Maximum Height of WCFZ}

In order to measure the maximum height of the WCFZ, it is necessary that the borehole height exceed the actual height of the WCFZ. Therefore, it is critical to estimate the height according to the reasonable processes from simple to complex, that is, from empirical formula and theoretical analysis to similar model experiment. 


\subsubsection{Empirical Formula Calculation and Theoretical Analysis of the Height of WCFZ}

From Figure 3, it can be seen the field geology engineering condition is to mine the thick coal seam with a thickness of $7.31 \mathrm{~m}$ adopting fully mechanized caving techniques. It is the common and most widely used to calculate using the calculation formula from the governmental code of The Regulations for Mining under Buildings, Water-bodies and Railways [39]. However, there is no exclusive formula for the fully mechanized caving mining method; it is usually substituted by the corresponding formula of one-time mining full height and slicing mining, respectively. There may be some errors about the result calculated. In order to reduce the errors, several prediction methods for the height of the WCFZ, i.e., the layered mining method in the 2017 edition of the Regulations, China university of mining and technology (Beijing) (CUMTB) method [9], and the Key Stratum discrimination method [40] are adopted to comprehensively predict the height of the WCFZ indoors, as shown in Table 1. The results calculated are shown in Table 2 below.

Table 1. Common empirical formulas and key stratum (KS) theory analysis for calculating the height of the water-conducting fracture zone (WCFZ). CUMTB: China University of Mining and Technology (Beijing).

\begin{tabular}{cccc}
\hline $\begin{array}{c}\text { Lithology of } \\
\text { Overburden }\end{array}$ & Calculation Formula & $\begin{array}{c}\text { Formula Serial } \\
\text { Number }\end{array}$ & Source \\
\hline Medium hard lithology & $H_{f}=\frac{100 M}{0.26 M+6.88} \pm 11.49$ & (a) & CUMTB [9] \\
Hard rock & $H_{f}=\frac{100 M}{1.2 \sum M+2.0} \pm 8.9$ & (b) & Regulations 2017 Edition [39] \\
Hard rock & $H_{f}=30 \sum M+10$ & (c) & Regulations 2017 Edition [39] \\
& $\begin{array}{c}\text { Discriminant criteria: } \\
(7 \sim 10) M\end{array}$ & & Key Strata method [40] \\
\hline
\end{tabular}

Where $M$ is the thickness of coal seam, $\mathrm{m} ; \sum M$ is the cumulative mining thickness, $\mathrm{m}$, taking the maximum value; and $H_{f}$ is the height of the WCFZ, $\mathrm{m}$.

Table 2. Height of the WCFZ by empirical formula and theory.

\begin{tabular}{cccccc}
\hline Formula Source & No. & Calculated & $\begin{array}{c}\text { The Larger } \\
\text { Value }\end{array}$ & Average Value & HWCFZ \\
\hline & & $\backslash \mathrm{m}$ & $\backslash \mathrm{m}$ & $\backslash \mathrm{m}$ & $\backslash \mathrm{m}$ \\
CUMTB & (a) & $71.7 \sim 94.7$ & & 83.4 & \\
Regulations 2017 Edition & (b) & $59 \sim 76.7$ & 76.7 & 83.9 & 85.47 \\
Regulations 2017 Edition & (c) & 91.1 & 91.1 & 85.47 & \\
Key Stratum method & & 85.47 & 85.47 & \\
\hline
\end{tabular}

The key stratum discrimination method [40] predicts the height of the WCFZ by the location of key stratum of overburden. According to this theory, the stratum that controls the movement of the whole or partial overburden strata is defined as the key stratum (KS); the former is defined as primary key stratum (PKS), while the latter is defined as sub key stratum (SKS) [41]. When the PKS of overburden is within the critical height (7-10) $M$, the height will develop to the top of the bedrock; when the PKS of overburden is located beyond the critical height (7-10) $M$, the height will develop to the bottom of the nearest SKS above the critical height (7-10) $M$, and the height of the WCFZ is equal to the height of the SKS from the mining coal seam.

Since Formula (a) is for the strata of medium hard strata, the result calculated may be larger than that of the hard rock strata, so the average value of $83.4 \mathrm{~m}$ was taken; for the sake of safety factors, these were taken the large values of Formulas (b) and (c), respectively. Since Formulas (b) and (c) all belong to the Regulation of the 2017 edition, it was decided to take the average value of Formulas (b) and (c), and obtain $83.9 \mathrm{~m}$; from the point of the key strata (KS) theory, it was shown that the hard $\mathrm{K}_{7}$ sandstone with a vertical distance of $85.66 \mathrm{~m}$ from the 15 coal seam is the PKS, which is larger than the critical height of $73.1 \mathrm{~m}(7-10) M$. The closest sub key stratum (SKS) beyond (7-10) $M$ is No.18 medium and fine-grained sandstone stratum, which is $78.16 \mathrm{~m}$ away from the upper boundary of the coal seam, 
and it can be ascertained that its lower boundary is the height of the WCFZ-that is, $85.47 \mathrm{~m}$, all as shown in Figure 3.

The results of all three methods are basically consistent. Therefore, combining the empirical formula and theoretical calculation results, and taking the larger value, the indoors estimated height of the WCFZ in the 150,313 working face is $85.47 \mathrm{~m}$.

\subsubsection{Physical Model Simulation Experiment of the Height of WCFZ Based on BOFDA}

It is the same as BOTDR that BOFDA uses Brilliouin back scattering light to measure parameters, but BOFDA is of the double-end measuring mode which emitting optical signal at one end and receiving the signal at the other end. The most important advantage of BOFDA is that it has a higher spatial resolution of $0.2 \mathrm{~m}$ using stimulated Brillouin scattering light and Frequency domain analysis techniques. The detailed operation principle of BOFDA can referred to reference [7].

In order to successfully and precisely predict the height of the WCFZ in the 150,313 working face of Yinying Coal Mine, a physical model simulation experiment of the WCFZ was carried out by using the Brillouin optical frequency domain analysis technology (BOFDA) [7]. The test equipment model is fTB 2505, which is made by the FibrisTerre Company located in Berlin, Germany. fTB 2505 uses the powerful software of fTView to monitor and collect the strain data.

In the experiment, a 1:150 geometric similarity ratio, 1:1 density similarity ratio, 1:12.25 time similarity ratio, and 1:150 elastic modulus strength similarity ratio were used. The testing fiber adopted in the experiment is $2 \mathrm{~mm}$ polyurethane fiber. There were 5 vertical optical fibers and 4 horizontal optical fibers pre-arranged between the open cut and stopping line of the similar model, the size of the model had a length $\times$ width $\times$ height of $4200 \mathrm{~mm} \times 250 \mathrm{~mm} \times 1600 \mathrm{~mm}$, as shown in Figure $5 \mathrm{a}$. The fibers were used to monitor the strain change of the optical fiber in the process of 45 times of excavation according to the $30 \mathrm{~mm}$ mining interval. The height of the WCFZ of the FV3 vertical fiber strain characterization is the largest, as shown in Figure $5 b$.

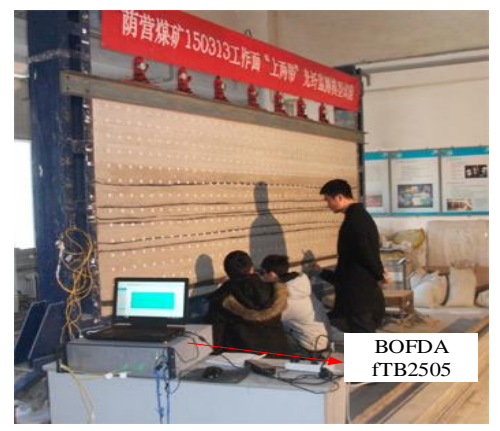

(a)

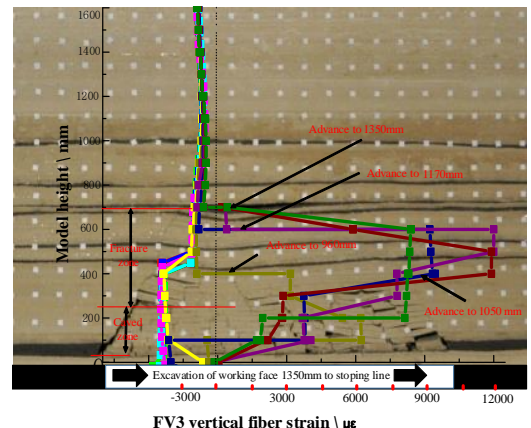

(b)

Figure 5. The physical model simulation experiment based on 150,313 working face monitoring based on Brillouin optical frequency domain analysis (BOFDA): (a) The layout of the BOFDA physical model experiment; (b) The dynamic height of the WCFZ characterized by FV3 Fiber Strains.

In the experiment, the height of the WCFZ increases with the advance of the working face. When the advance is $1350 \mathrm{~mm}$, the height of the WCFZ is stable at the model height of $700 \mathrm{~mm}$, and the height of the coal seam floor is $601.8 \mathrm{~mm}$; at this time, the height of the caving zone develops to the model height of $300 \mathrm{~mm}$, and the height of the floor is $201.8 \mathrm{~mm}$.

As there is only a spatial resolution of $0.2 \mathrm{~m}$ of the BOFDA and the excavation method was adopted is one-time mining full height instead of top-coal caving, the height of the WCFZ obtained from the experiment is larger than the actual height, but it is in line with the scope of the above 
calculation. The experiment height that served as the upper limit of the WCFZ is in line with the actual production practice, that is:

$$
\left\{\begin{array}{l}
\text { Height of caving zone }<30.27 m \\
\text { Height of } W C F Z<90.27 m
\end{array} .\right.
$$

\subsubsection{Drilling Height for Testing the Height of WCFZ}

Considering the empirical formula, theoretical analysis, and physical model test, the pre-estimated height of the WCFZ can be arrived at $85.47 \mathrm{~m}$. As the borehole is set on the roof of the air intake roadway, the borehole vertical height can be determined as $82.47 \mathrm{~m}$ by subtracting the height of the coal roadway from the calculated height.

In practice, the condition that the length of the borehole exceeds the converted length of its vertical height must be satisfied. So, in order to predict the accurate height of the WCFZ, it is adopted that the redundant value is $15 \%$ higher than the estimated vertical height to design the actual vertical height. Finally, it is determined that the vertical height of the borehole is $95 \mathrm{~m}$.

\subsection{Design of the Drilling Occurrence}

\subsubsection{The Location of Borehole Drilling}

It is not only the lowest cost of manpower, time, and money expense to drill boreholes vertical to the mining direction of the working face when drilling boreholes is performed from the roof of the air-intake roadway upwards to overburden in reality, but it is very convenient for drillers to conduct the drill operation and the management of the coal mining as well. The most important is that it is also very beneficial to the optical cables layout through PVC pipes and the monitoring of the optical fiber strain later. Therefore, it is determined that the roof of the air-intake roadway is where the borehole is operated in the process of new approach. Next, the drilling occurrence is to be studied and designed to predict the maximum height of the WCFZ and suffer the least damage to the borehole and optical cables.

\subsubsection{The Distribution of the Maximum Height of WCFZ within the Overburden in Reality}

It has been described and confirmed that the WCFZ is in a saddle shape in the direction and tendency of the working face by previous production practice and indoor model simulation experiments [14]. The maximum height of the WCFZ occurs above the open cut and final mining position in the direction of the strike, and it occurs above the mining upper boundary in the inclined direction. So, the maximum height of the WCFZ is usually developed along the strata collapse line in the inclined direction of the working face, and it is at the upmost positon of the collapse line, as shown in Figure 6.

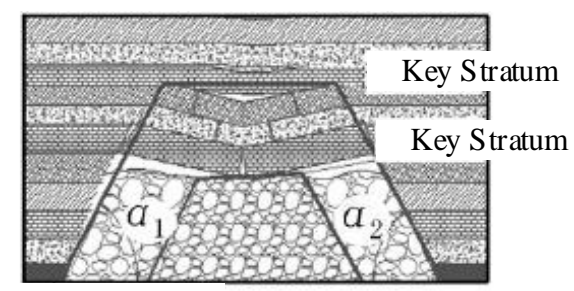

Working face

The profile shape of initial periodic weighting of working face along the strike

(a)

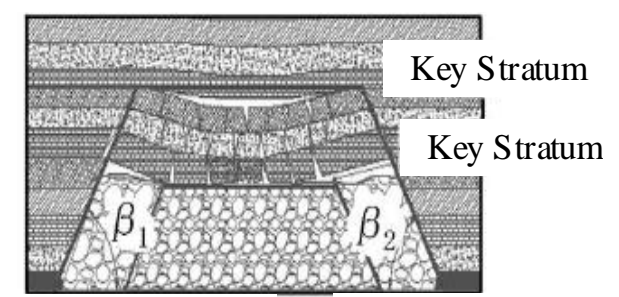

Return air lane Air inlet

Profile shape along the dip direction

(b)

Figure 6. Schematic diagram of overburden collapse form of a longwall coal mining working face: (a) The direction of the strike; (b) The inclined direction of the working face. 
Therefore, the maximum height of the WCFZ can be obtained only when the drilling holes are arranged parallel to the collapse line and as close to the collapse line as possible. Secondly, in order to prevent the bottom parts of the cables from being broken when the overburden collapses, the borehole dip angle should be slightly smaller than the caving angle of the overburden, as shown in Figure 7. There are 2 benefits to the borehole being set close to the goaf and the collapse line. On the one hand, the development process of the maximum height of the WCFZ in its whole developing period can be completely monitored; on the other hand, it causes the least stress of the optical fiber caused by the strata collapse and fracture, so that the optical cables will not break in the process.

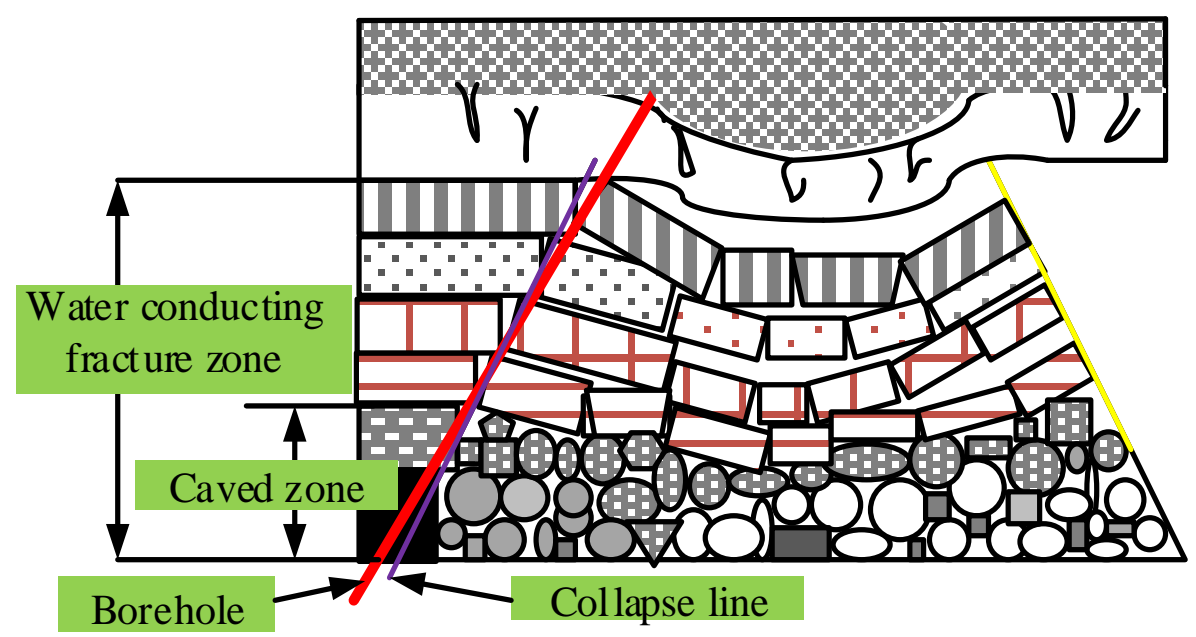

Figure 7. Division of overburden movement and layout of drilling holes.

The reason is that the collapsed strata layer in the goaf and the fractured strata layer in the fractured zone are bound to cause the horizontal stress effect on the rock strata near the borehole.

The optical cables embedded in the borehole will generate the strain under the action of gravity and horizontal stress, as shown in Figure 7. According to this arrangement, the cables in the borehole are less stressed, and they are not directly dragged by the rock collapse, which is conducive to the protection of optical cables.

\subsubsection{The Drilling Occurrence in the Field Experiment}

According to the similar physical model experiment and production practice of the 150,313 working face, it was found that the collapse angle of overburden in the inclined direction is usually $62-63^{\circ}$. Therefore, the design of drilling angle was carried out according to $60^{\circ}$ slightly smaller than the caving angle in reality. The lower part of the optical cables was outside the caving zone, and the stress caused by the collapse of the rock strata was very small, as shown in Figures 3 and 7; the middle and upper part of the optical cables in the borehole were within the caving zone and fractured zone of the overburden, and they suffered strain changes, which can reflect the maximum height development of the WCFZ. As the drilling angle was $60^{\circ}$, the vertical estimated height of the drilling hole was $95 \mathrm{~m}$, so the value of $110 \mathrm{~m}$ was decided to be the designed length of the drilling borehole.

For the underground drilling in coal mines, it is the most optimistic if there are drilling fields available within the protective coal pillars. The drilling can be arranged according to Figure 7; however, it is a more convenient, quick, and economic feasible resort to drill in the gateroad of the working face. It is also welcomed by the drilling miners to drill from the gateroad roof to the overlying rock in the field prediction experiment.

In this paper, the predicting borehole was designed in the air-inlet gateroad (haulage roadway) of the 150,313 working face. The final drilling design scheme of this experiment was as follows: the designed location was $550 \mathrm{~m}$ away from the open cut, the drilling direction was perpendicular to the mining direction of the working face, the drilling dip angle was $60^{\circ}$, the drilling length was $110 \mathrm{~m}$, 
the drilling vertical control distance was $95.26 \mathrm{~m}$, and the horizontal control distance was $55 \mathrm{~m}$. It is guaranteed that the drilling hole was nearly parallel and as close to the overburden collapse line as possible. It is illustrated by the three-dimensional diagram of the borehole layout in Figure $8 \mathrm{a}$ and the plane diagram of the stratum profile of borehole arrangement in Figures 3 and $8 \mathrm{~b}$.

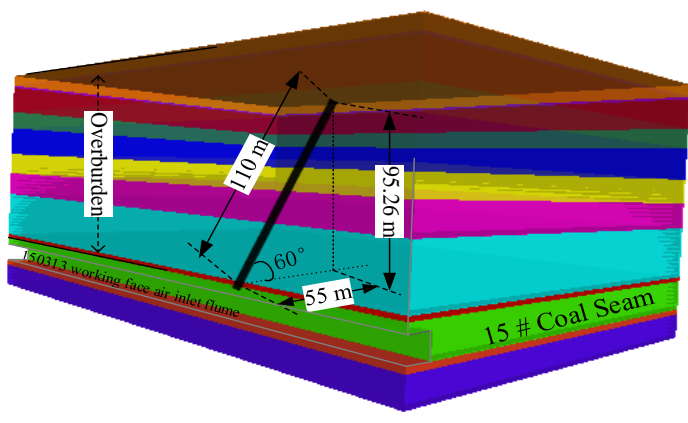

(a)

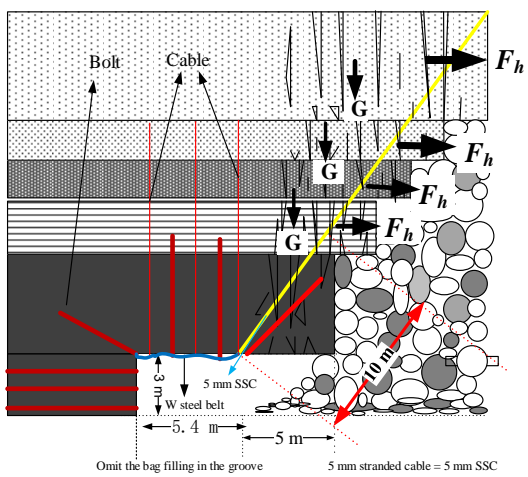

(b)

Figure 8. The diagrams of the layout of the borehole: (a) The 3-D description diagram; (b) Description of transverse section of the gateroad.

\subsubsection{Drilling and Optical Cable Protection}

Especially for the 150,313 working face in this field experiment, the geology and production condition are the $7.31 \mathrm{~m}$ thick coal seam mined using top-coal caving, overburdens of hard and ultra-thick limestone and sandstones, and so on, which resulted in that the strength of overburden fracture and caving were violent and intense [12]. Therefore, for preventing the low parts of optical cables from being damaged and broken within the caving zone, special drilling protection measures were elaborate designed to withstand intense and violent overburden collapse. The special countermeasures were made as described below.

In the field experiment conducted in the 150,313 working face, it was arranged that the rock bots and anchor cables were not taken back nearby the borehole on both the roof and coal pillar when the working face passed the borehole. In addition, the top coal man-caving within the distance of $5 \mathrm{~m}$ from the coal wall into the goaf was not implemented, and the minimum mining height that the shearer and the support can pass through was calculated, as shown in Figure $8 \mathrm{~b}$ above. After the working face passed through the borehole, gunny bags full of the coal cinder were used to fill un-caved space in the area of the roadway in case of the roof settling quickly and preventing the corresponding gas accumulation at the same time.

So, it was clear and verified that roofs nearby the borehole formed a stable cantilever beam structure ultimately, which resulted in gradually rotating and sinking to the goaf, and slowly touching the ground. There was neither the sudden overlying strata collapse in the gateroad and the goaf nearby the borehole nor optical cables failure within the caving zone, as shown in Figure $8 \mathrm{~b}$.

As the overburden outside the anchorage area was still in the range of the normal caving zone and fractured zone, after the adjacent overlying strata had broken into the caving zone and the fractured zone, the overburden nearby the borehole would be affected by the gravity $G$ and the horizontal stress $\boldsymbol{F}_{\mathbf{h}}$ caused by the collapsed strata, which caused the strain change of the optical fiber in the borehole. From Figure $8 \mathrm{~b}$, as the optical cables beyond the $10 \mathrm{~m}$ length of the borehole were still in the range of the caving zone and fractured zone, there was little effect on the development and monitoring of the height of the WCFZ. Therefore, the drilling protection countermeasures can be used to dynamically and quantitatively monitor the height development and change of the WCFZ. 


\subsection{Selection of Sensing Optical Cables}

In order to meet the requirements of optical fiber layout under the condition of large deformation, a thick coal seam, and a thick and hard overburden of caving mining, the $5 \mathrm{~mm}$ steel strand (SS) optical cable was selected for the field prediction. The reasons were the mechanical and physical characteristics of optical cables-to sum up previous practice $[25,28]$, the results of indoor and field test research [12], etc. The structure and physical object of the optical fiber are shown in Figure 9, and its physical parameters are shown in Table 3.

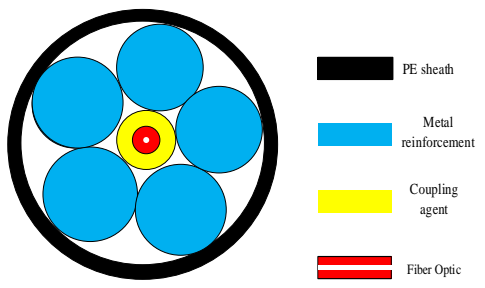

(a)

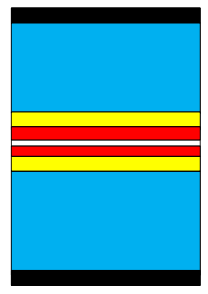

(b)

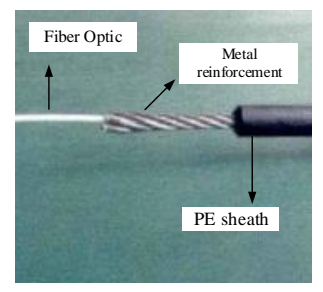

(c)

Figure 9. Structural and physical drawing of $5 \mathrm{~mm}$ steel strand optical cable: (a) Cross-sectional structure diagram; (b) Longitudinal section structure diagram; (c) $5 \mathrm{~mm}$ optical cable physical picture.

Table 3. Physical and mechanical property parameters of $5 \mathrm{~mm}$ steel strand optical cable.

\begin{tabular}{cccccc}
\hline $\begin{array}{c}\text { Cable } \\
\text { Diameter }\end{array}$ & $\begin{array}{c}\text { Core } \\
\text { Diameter }\end{array}$ & $\begin{array}{c}\text { Tensile } \\
\text { Strength }\end{array}$ & $\begin{array}{c}\text { Elastic } \\
\text { Modulus }\end{array}$ & $\begin{array}{c}\text { Unit } \\
\text { Weight }\end{array}$ & $\begin{array}{c}\text { Operating } \\
\text { Temperature }\end{array}$ \\
\hline$\backslash \mathrm{mm}$ & $\backslash \mathrm{mm}$ & $\backslash \mathrm{N}$ & $\backslash \mathrm{GPa}$ & $\backslash \mathrm{kg} / \mathrm{km}^{3}$ & $\backslash^{\circ} \mathrm{C}$ \\
5.0 & 0.9 & 6500 & 42 & 38 & $0-80$ \\
\hline
\end{tabular}

It was verified and confirmed that the strain coefficient of the SS fiber is $0.04954 \mathrm{MHz} / \mu \varepsilon$ and the strain transfer efficiency is 0.9968 through the actual indoor optical fiber performance experiment. It was also confirmed and validated that the $5 \mathrm{~mm}$ SS fiber has a capacity that is much better coupled with concrete in the process of concrete deformation during the experiment of the pulling-out process of concrete column [12]. It also showed that the $5 \mathrm{~mm}$ SS fiber with higher strength has higher tensile and breaking resistance, which is suitable for embedding in the rock strata to characterize the large deformation of the rock strata.

It was indicated that the SS cable had better overall monitoring performance than the GFRS and $10 \mathrm{~m}$ fixed point cables via comprehensive analysis on strength and accuracy indicates in field validation [28]. It was also demonstrated that the SS cable expresses many more rich strain details, larger strain range, and higher tensile performance than the $2 \mathrm{~m}$ fixed point cable [12]. So far, using the SS cable for the field prediction of the height of the WCFZ is the most suitable choice from the viewpoint of literature references, field experiments, indoors fiber performance tests, and physical and mechanical properties.

These SS optical cables were made by the Nanzhi Company in China; the fabrication of the SS optical cables is introduced briefly and the mainly specific production process of this SS cables is as follows.

The first step is the preparation of a sensing fiber core, that is to make a standard single-mode sensing optical fiber with cladding and sheath.

The second step is the optical fiber stranding and implantation. In this step, the sensing optical fiber with a sheath is placed in the center of the 7-core stranded wire; 6 metal wires are twisted at the periphery according to the unified direction and a certain angle, and they are tightly wound on the straight sheathed optical fiber to form a rope or cable shape. In the implementation process, the sensing fiber is always straight to ensure the smooth optical path. The implementation of this process can be 
realized by a universal stranding machine, or the sensing core can be implanted into the stranded wire by detaching the metal cable.

The third and final step is the over plastic protection. In the final step, the processed sensing cable is covered with PVC, polyethylene (PE), and other high-strength plastic protective layers. On the one hand, it can improve the integration degree of the metal wire and fiber core, prevent the metal strand from falling off due to improper construction, and further increase the overall strength of the optical cable. On the other hand, it can greatly improve the ability of the overall coordinated deformation of the optical cable, especially to overcome the stress accumulation phenomenon when the optical cable deformation is large.

\subsection{The Layout of the Experiment and the Layout of Field Optical Cables}

Taking advantage of the BOTDR single-ended mode, the optical fiber layout and monitoring system layout are shown in Figure 10a. It can be seen that there are two boreholes; one is the previous for the overlying strata movement, the other is for prediction of the height of the WCFZ in this paper, and the two boreholes were at a distance of $250 \mathrm{~m}$. All the boreholes were located in the air-intake gateroad of the 150,313 working face. The SS cable was embedded in the new borehole with a length of $110 \mathrm{~m}$, a dip angle of $60^{\circ}$, and vertical to the advancing direction of the working face shown in Figure 10b.

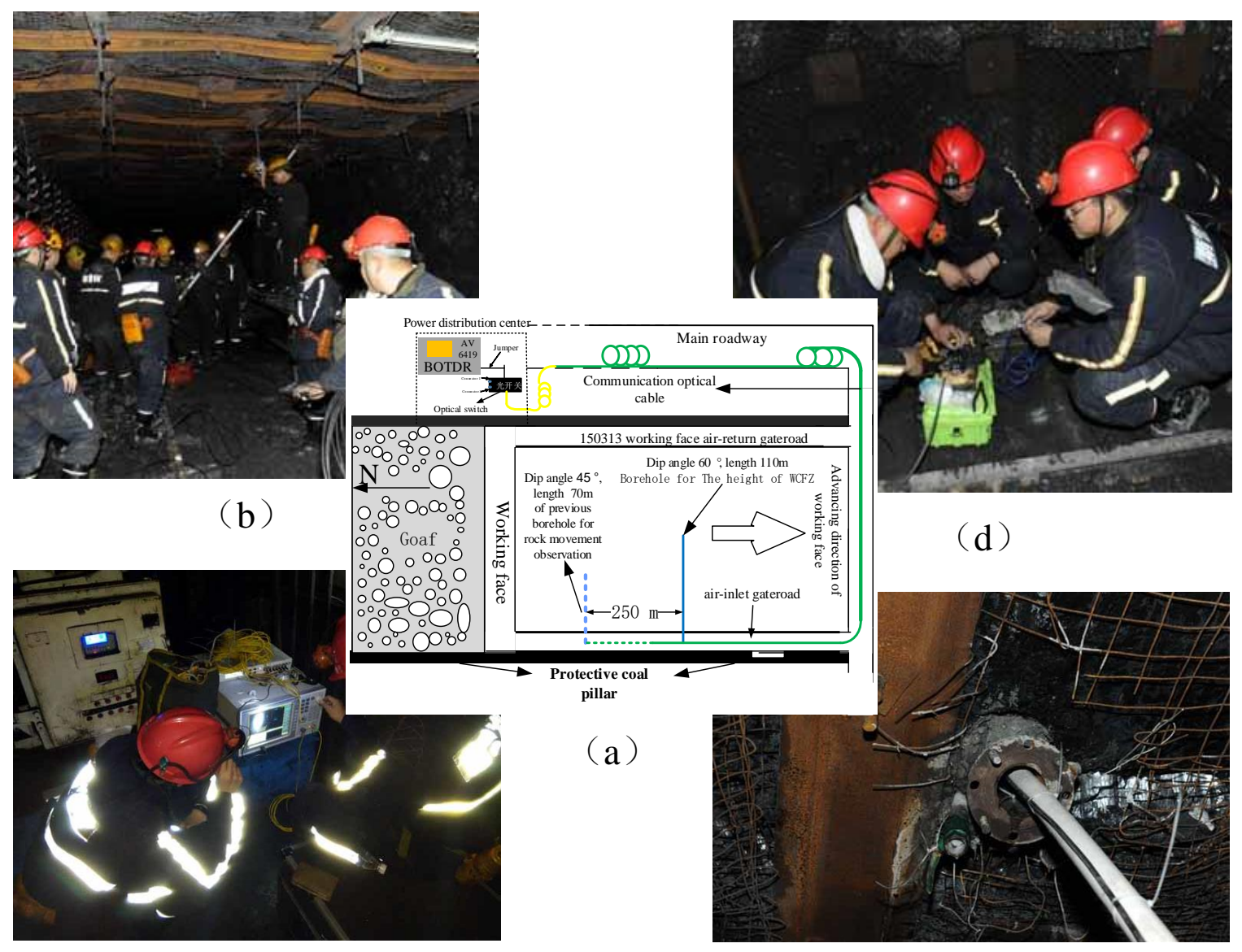

(c)

(e)

Figure 10. Illustrations description of the field BOTDR monitoring system and optical cables layout: (a) Layout of system; (b) The overall view of the borehole and fiber installation; (c) The steel strand (SS) cable was fused with the common optical cable; (d) Monitoring strain in the distribution center; (e) The PVC pipe bounded with SS cable in the borehole. 
The SS optical cable and the communication cables were fused together as shown in Figure 10d, and the communication cables were laid out to the power distribution center through the main roadway. The monitoring station was there, as shown in Figure 10c. The SS cable was installed into the borehole via PVC pipes, and the cables were bounded to its surface with plastic ropes, as shown in Figure 10e. When the pipes were installed into the borehole, the borehole was grouted with the similar strength concrete with the overlying strata.

The specific deployment steps of $5 \mathrm{~mm}$ SS optical cables were as follows:

(1) According to the aforementioned parameters, the borehole was drilled at the point of the 440 rows of W steel strips was, which was $550 \mathrm{~m}$ away from the open cut in the air-inlet gateroad as shown in Figure 10a,b.

(2) After drilling implemented, cleaning the hole carefully using the drill bit as soon as possible.

(3) The SS cable was bound outside of $\Phi 40 \mathrm{~mm}$ PVC pipes with plastic ropes as shown in Figure 10e.

(4) Deploying the PVC pipes into the borehole manually as shown in Figure 10b.

(5) After all PVC pipes were delivered to the bottom of the hole, the orifice of the borehole should be sealed with a borehole sealer and grouted with plain concrete slurry.

(6) Finally, the communication optical cable was fused with the SS cable, as shown in Figure 10d, and then led to the power distribution center of the main transportation roadway to establish the monitoring station, as shown in Figure 10c.

It was 1 October 2019 when the new drilling construction, optical fiber layout, and grouting consolidation were completed. At that time, the working face was $-200 \mathrm{~m}$ away from the new borehole. One week later, the initial strain of the optical fiber was measured, and the spatial position of the optical fiber was calibrated. Specifically, all the strain mentioned is the relative value of the tested strain subtracted from the corresponding initial strain in the paper.

After the working face passed through the drilling hole, the personnel miners of the colliery filled the un-caved space in the gateroad, and it was confirmed that the un-caved space of the gateroad was filled full and substantial, and the anchor bolts and anchor cables nearby the borehole remained as before.

\subsection{The Field Monitoring and Data Collection Based on BOTDR}

The strain analyzer of Av6419 based on BOTDR was adopted for data acquisition, and its main technical parameters used in the experiment are shown in Table 4.

Table 4. Parameters used of AV6419 in the test.

\begin{tabular}{cc}
\hline Parameters & Specifications \\
\hline Measuring range $(\mathrm{km})$ & 5 \\
Spatial resolution $(\mathrm{m})$ & 0.20 \\
Pulse width $(\mathrm{ns})$ & 20 \\
Measurement range $(\mu \varepsilon)$ & $-15,000-+15,000$ \\
Sampling frequency range $(\mathrm{GHz})$ & $10.45-12.00$ \\
Wavelength of pulse light $(\mathrm{nm})$ & $1550 \pm 5$ \\
\hline
\end{tabular}

Since the thermal conductivity of formation rock is very small, the temperature of the overburden nearby the borehole changed little during the experiment, and the measured strain of the optical cable is usually far greater than the influence of the temperature change of the rock mass. Therefore, the influence of temperature variation on the measurement results can be ignored.

It was the beginning of November 2019 when the optical fiber strain monitoring started. The testing frequency was 2-3 times/week in the early stage, when the working face was close to the borehole, and the data acquisition frequency was encrypted to once a day. The actual effective test distance was 
approximately $-100 \mathrm{~m}$ to $+42 \mathrm{~m}$ between the working face and the borehole. Negative value refers to an advanced drilling hole, and positive value refers to past the borehole.

\section{Analysis of Field Test Results}

\subsection{Optical Fiber Strain Distribution and Varying Characteristics}

In this paper, the positive strain means tensile strain, and the negative strain is compressive strain; if not specified, the strain mentioned in this paper is the relative strain, in which the initial strain is subtracted from the test strain.

Based on the new approach with the optimized process proposed in this paper, under the protection of safety measures, the optical fiber strain in the borehole varied without breakage in the whole period of rock collapse and deformation, and the optical fiber strain characterized the distributed dynamic development law of the height of the WCFZ in time and space, as shown in Figure 11.

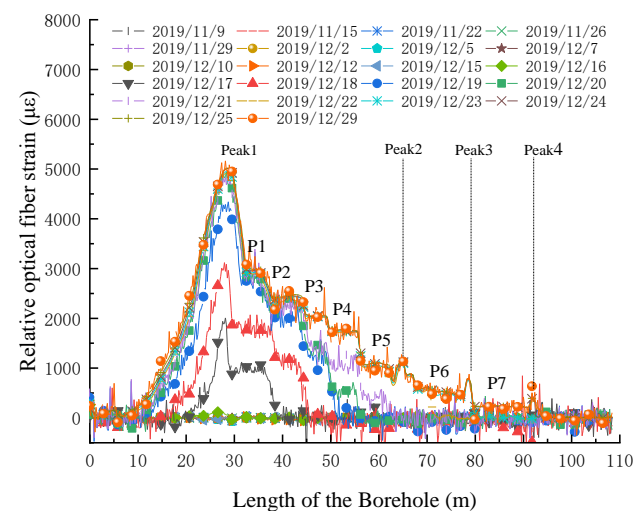

(a)

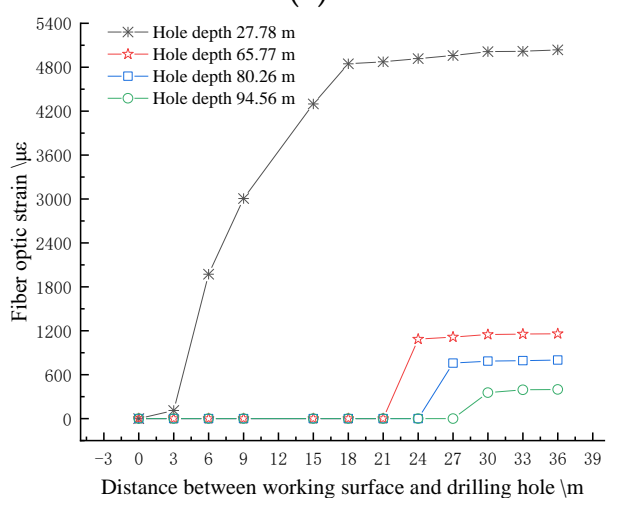

(c)

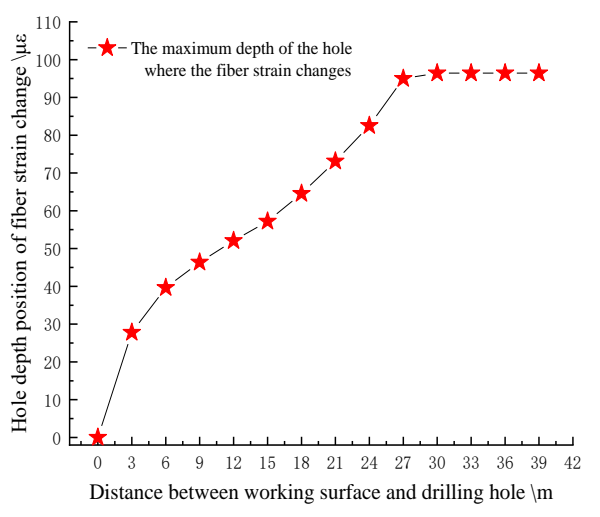

(b)

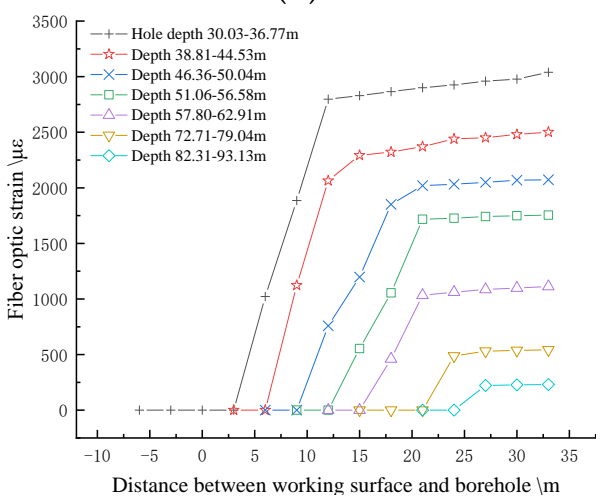

(d)

Figure 11. Strain curves of $5 \mathrm{~mm}$ stranded steel cable in borehole: (a) The overall strain curve; (b) The depth of the strain change of the optical fiber in the borehole; (c) Variation curve of peak strain with advancement of working face; (d) The average strain change curve of the strain platform as the working surface advances.

It can be seen that in terms of time occurrence, before the working face passed through the borehole, there was no strain variation of the optical fiber prior to 15 December from Figure 11.

After the working face passed through the borehole for $3 \mathrm{~m}$ on 16 December, the tensile strain curve gradually increased with the advancing of the working face. After the working face passed through the borehole for $15 \mathrm{~m}$ on 20 December, the strain increasing speed slowed down and the change amplitude decreased a lot. After the working face passed through the borehole for $30 \mathrm{~m}$ on 25 December, the optical fiber strain was basically stable, and there were no longer changes anymore, which indicates that the deformation and movement of the rock strata tended to be stable at this time, 
as shown in Figure 11a. From the viewpoint of spatial development, the strain curve of the optical fiber changed from the initial state near the orifice to the state of strain increasing gradually, reaching the maximum fiber strain peak at the hole depth of $27.78 \mathrm{~m}$; then, with the increase of hole depth, the strain of optical fiber turned to decrease in a state of ladder-which was likely until the initial strain state without strain change, as shown in Figure 11a. That indicated two things: the first was that the hole depth of $27.78 \mathrm{~m}$ is the location where the deformation and displacement of the strata were relatively large, and the second was that this hole depth was the boundary point between the violent and moderate activity areas of the different strata.

As shown in Figure 11b, the optical fiber strain height in the borehole increased with the advance of the working face. After the working face passed through the borehole for $27 \mathrm{~m}$, the strain of the optical fiber develops to $94.97 \mathrm{~m}$ of the hole depth, and then the variation amplitude decreases greatly. After the borehole passed through the borehole for $30 \mathrm{~m}$, the strain height of the optical fiber only increased slightly, and it finally stopped at $96.42 \mathrm{~m}$. It showed that this height was the maximum hole depth of rock deformation, and it also showed that the rock deformation evolved gradually from the orifice to the bottom of the hole step by step, and the failure deformation of the overburden changed gradually from the bottom to the top.

It can be seen that there are two kinds of curves of fiber strain: peak and platform. As shown in Figure 11a, the peaks were at $27.78 \mathrm{~m}, 65.77 \mathrm{~m}, 80.26 \mathrm{~m}$, and $94.56 \mathrm{~m}$ in the borehole depth, which are marked as peak1 to peak4. From Figure 11c, the peak value for every single strain peak increased with the advance of the working face; peak1 reached $4847 \mu \varepsilon$ after the working face passed through the borehole for $18 \mathrm{~m}$, this was the maximum tensile strain. Then, there was no longer any increment and the strain was maintained as basically stable later. Peak2 appeared when the working face passed through the borehole for $24 \mathrm{~m}$, and the strain increased from 1085 to $1149 \mu \varepsilon$ when the working face passed through the borehole for $30 \mathrm{~m}$, and then the strain was kept stable. Peak3 and Peak4 strain peaks appeared when the working face passed through the borehole for $27 \mathrm{~m}$ and $30 \mathrm{~m}$, respectively, and the peaks were $758 \mu \varepsilon$ and $355 \mu \varepsilon$ respectively, and then the peak height did not change any more, as shown in Figure 11c.

It also can be seen in Figure 11a that the strain distribution curves of the optical fiber showed seven strain platform intervals. They are located in the section of the hole depth of 30.03-36.77 $\mathrm{m}$, 38.81-44.53 m, 46.36-50.04 m, 51.06-56.58 m, 57.8-62.91 m, 66.79-71.28 m, and 82.31-93.13 m respectively, which were recorded as P1-P7. The strain variation of each strain platform curve is shown in Figure 11d. It can be seen that platforms appeared successively from the bottom to top as the working face advanced; the change of tensile strain of every single platform increased gradually with the advancing of working face, which indicated that the degree of deformation and failure of rock strata increased with the advance of working face, but it did not change after increasing to a stable value. The overall strain of the platforms P1-P7 decreased gradually from the bottom to top, indicating that the failure of rock strata occurred from the bottom to the top, while the degree of deformation and failure of rock strata decreased from the bottom to the top, too.

Previous studies have shown that the peak value of optical fiber strain in the rock stratum indicates that the optical fiber suffered from greater stress, which often occurs in the position where the rock stratum separated and the rock stratum was damaged greatly. The strain platform curve shows that the stress of the optical fiber suffered is relatively uniform, which indicates that the damage of the rock strata is in an overall state of change. In order to study the relationship between optical fiber strain changes and stratigraphic correlation, the deformation and movement of the overburden which caused various optical fiber strain changes were studied in detail by projecting the optical fiber strain change curves onto the stratigraphic profile.

\subsection{Relationships between Strain Distribution of Borehole Optical Cable and Stratigraphic Correlation}

According to the occurrence of the borehole, the length of optical cables in the borehole, and various geological reports of the working face, the distribution curves of optical fiber strain changes were 
projected to the stratigraphic column profile of working face 150,313, and the correlation map of optical fiber strain and stratigraphic in the borehole was obtained, as shown in Figure 12.

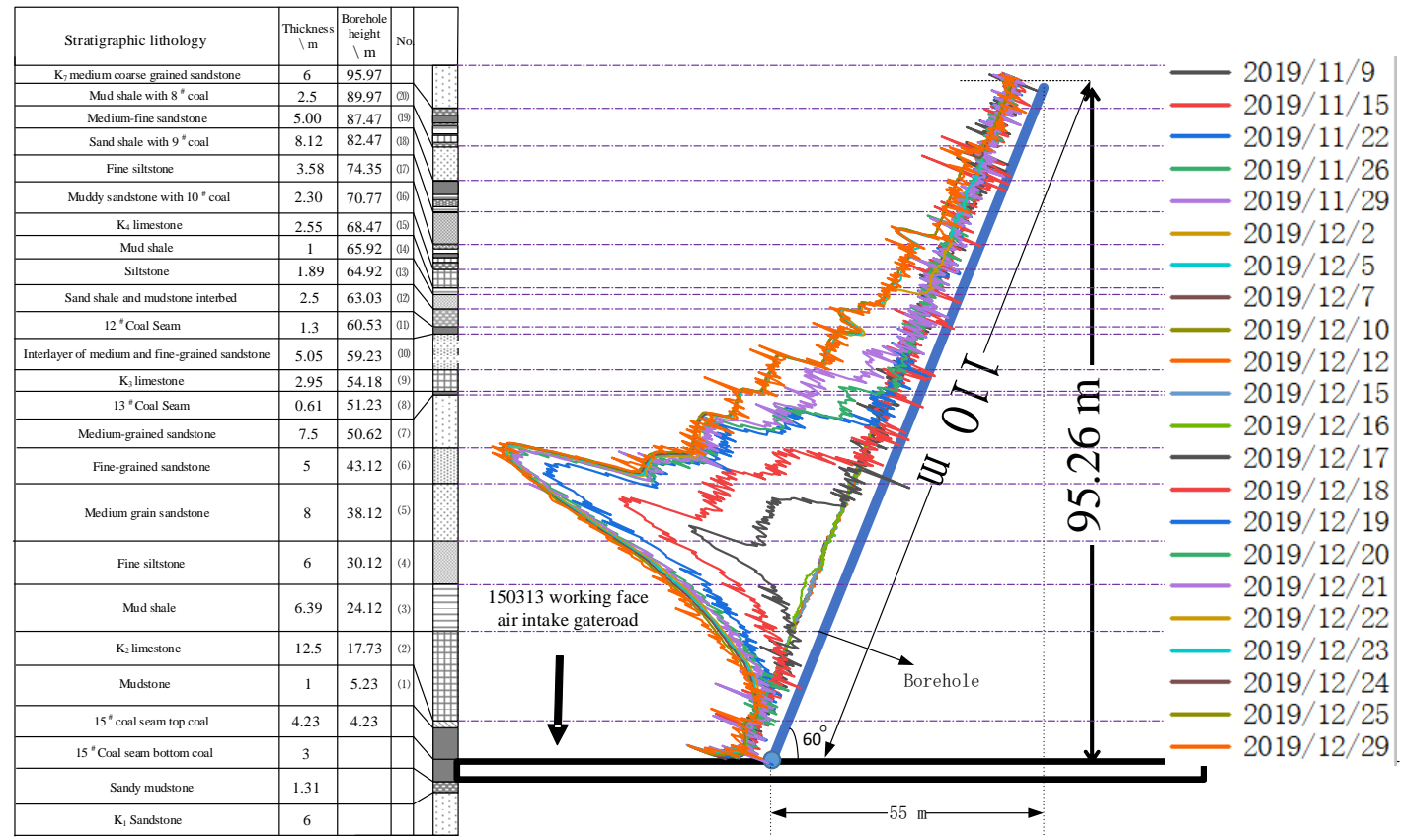

Figure 12. Comparison between optical fiber strain in borehole and strata within the WCFZ.

The movement and deformation of overburden affected by mining can be reflected and characterized by the variation of the optical fiber strain. Before the working face passed through the borehole on 15 December, the optical fiber in the borehole presented the initial strain state, indicating that under the support of the advanced moving support, rock bolts, and anchor cables, under the protection of the overlying hard limestone and various sandstone layers, the compressive strain phenomenon of the advance supporting stress was not shown, and the overlying strata are in a stable state nearby the borehole. Only on 16 December did the tensile strain of optical fiber began to change obviously after the working face passed through the borehole for $3 \mathrm{~m}$, as shown in Figure 12.

It is shown in Figure 12 that the peak value of optical fiber strain peak1 was located in the upper part of the No.3 shale layer with soft lithology, which was due to the large deformation of the shale layer and large collapse strength; on the other hand, it showed that there was a large separation between the underlying No. 3 stratum and the overlying No.4 stratum. The optical fiber strain peak2 was located at the bottom of the No. 10 medium-grained and fine-grained sand shale interlayer, which indicated that the exact position of the peak should be located in the soft shale in the interlayer. This showed that under the influence of mining, the No.10 rock layer had a large internal separation; peak3 was located in the lower part of the No.16 muddy sandstone layer, which indicated that under the protection of the overlying primary key stratum and sub key strata, there were only inner interlayer separations within the lower part of this stratum. Peak 4 was located in the upper part of the No.18 sandstone shale bearing 9 coal, which indicated that there was a large separation between the underlying No.18 and the overlying No.19 medium and fine-grained sandstone layer. The overlying rock layers over peak4 were in a stable original stratum state all the time. Generally speaking, the peak of fiber strain was located in the layered strata with soft lithology, while the position of the peak was also the boundary position of different lithology - that is, the position of the strata separation.

The region where the optical fiber strain appeared to be a platform curve and then changes was located in various sandstone layers with high lithological strength, as shown in Figure 12. As a whole, under the drilling layout and optical fiber strain monitoring approach proposed in this paper, the tensile strain of the optical fiber in the hard rock layer showed the platform curve. At the same time, 
Figure 12 showed that the inflexion position of the strain platform curve was basically the position of different rock stratum interfaces; according to the inflexion point of the optical fiber strain platform, the strata stratification and separation can be distinguished, too.

\subsection{Optical Fiber Strain Characterization of the Movement and Deformation within Overburden}

It can be seen from Figure 12 that with the mining of the working face, the distribution variation of the optical fiber strain in the borehole showed three distinct parts.

- The first part: the whole of fiber strain showed a curve that gradually increased from bottom to top that was in the No.1 to No.3 rock formations, and the optical fiber strain reached the maximum strain peak in the upper part of the No.3 rock formation.

- The second part: the whole of fiber strain was irregular step-like decent curves that gradually decreased from the No.4 rock formation to the No.18 rock formation.

- The third part: the fiber strain basically showed the initial strain state from the No. 19 rock formation to the upper formations.

It showed that the first part belongs to the caving zone where the overburden strata gradually collapsed from bottom to top after the goaf formed; the second part belonged to the fractured zone where the overburden fractured, rotated, and sunk, and the strength of the fracture failure gradually decreased from the bottom to top; the third part is the subsidence bending zone where the rock strata were protected by the primary key layer, while the rock layers were in stable state all the time.

\subsection{Determination of the Height of WCFZ in the Field BOTDR Monitoring Experiment}

According to the above discussion and the analysis shown in Figures 11 and 12, it can be seen that in the approach proposed in this paper, the height of the WCFZ can be comprehensively determined according to the height of the fiber strain in the borehole, the position of the peak value of the optical fiber strain, etc.

- $\quad$ Figure $11 \mathrm{~b}$ shows that the strain height of the optical fiber in the borehole developed to $94.97 \mathrm{~m}$ after the working face passed the borehole for $27 \mathrm{~m}$, and then the variation amplitude decreased greatly. After the working face passed through the borehole for $30 \mathrm{~m}$, the strain height of the optical fiber did not increase any more, and it finally stopped at $96.42 \mathrm{~m}$. It is preliminarily determined that the measured height of the WCFZ is $94.97-96.42 \mathrm{~m}$ in hole depth.

- Due to the separation between the rock layers, the tensile stress concentration of the rock strata at both ends on the optical fiber appears, forming the peak tensile strain of the optical fiber. According to Figure 11a,c, the optical fiber strain reached the maximum at the hole depth of $27.78 \mathrm{~m}$, and it can be preliminarily determined that this position is the measured height of the caving zone in borehole depth. As shown in Figure 11c, the highest position's peak is peak 4 at the hole depth close to $94.56 \mathrm{~m}$, which indicates that this is the position of the strata separation from the upper strata, and the optic fiber strain above peak 4 kept the stable initial state all the time. It can also be determined that this position of $94.56 \mathrm{~m}$ is the measured height of the WCFZ. Therefore, the height of the caving zone is at the hole depth of $27.78 \mathrm{~m}$; the maximum height of the WCFZ is at the hole depth of 94.56-96.42 m.

So, the vertical height from the coal seam floor is $27.058 \mathrm{~m}$ and $84.891-86.502 \mathrm{~m}$ respectively by calculation conversion. The averaged value was taken for the convenience of application, and the maximum height of the WCFZ measured by BOTDR arrived at $85.697 \mathrm{~m}$. Based on the comparison of the key strata method, the empirical formula calculation method and similar model experiment results, the error between them and the measured height of the WCFZ can be obtained, as shown in the Table 5 below. 
Table 5. Judgment table for the HWCFZ in the 150,313 working face.

\begin{tabular}{cccc}
\hline Methods & Value $/ \mathbf{m}$ & In Situ $/ \mathbf{m}$ & Error $/ \%$ \\
\hline CUMTB & 83.4 & 85.697 & 2.68 \\
2017 Regulation & 83.9 & 85.697 & 2.096 \\
Key Stratum & 85.47 & 85.697 & 0.27 \\
Model Test & $<90.27$ & 85.697 & $<5.33 \%$ \\
\hline
\end{tabular}

It can be seen that compared with the results of empirical formula, key stratum discrimination height, and similar model test results, the maximum error is only $<5.33 \%$, which shows that all the four kinds of discrimination methods show a high degree of consistency, and the comparison proves that the height of the WCFZ measured by the field experiment is effective and feasible. The application of this field testing approach applied in the 150,313 working face is successful. Accordingly, it shows that the distributed optical fiber strain BOTDR testing approach based on the optimized process proposed in the paper is feasible and worthy of recommendation.

\section{Analysis of the Dynamic Evolution Law of the Maximum Height of WCFZ}

Through the analysis of the previous sections, we can get the law of the evolution process of the maximum height of the WCFZ and the height of the caving zone characterized by the borehole optical fiber strain, as shown in Figure 13.

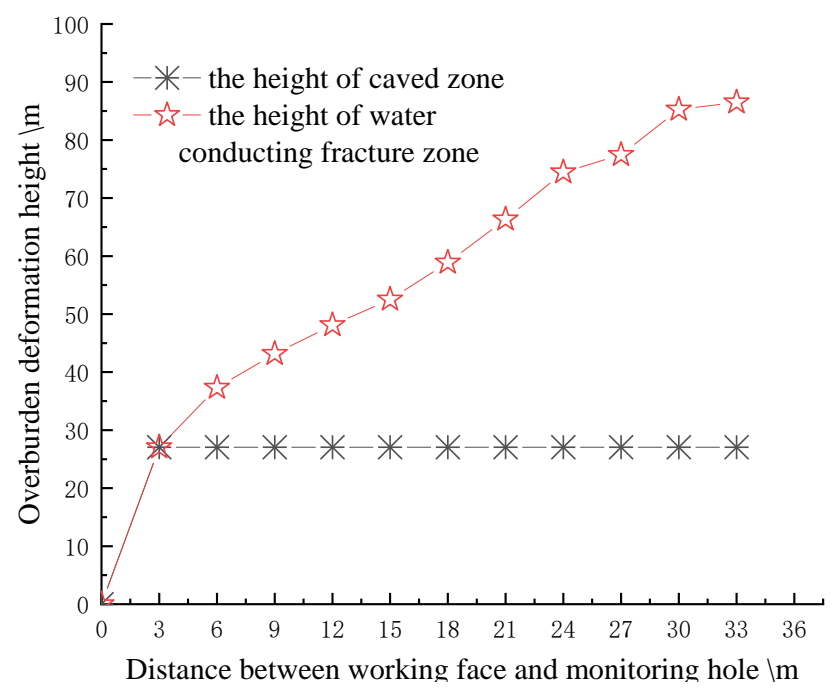

Figure 13. Curves of the height of two zones with mining of working face.

Based on the new approach proposed in this paper, Figure 13 shows that when the working face passed through the drilling, neither the advance support stress of the working face nor the compression strain of the optical fiber was obvious; only when the working face passed through the drilling for $3 \mathrm{~m}$ did the optical fiber tensile strain in the drilling turn out to be obvious. At this time, the height of the WCFZ developed to the borehole depth of $27.78 \mathrm{~m}$, and the height of the coal seam floor was $27.058 \mathrm{~m}$. Later, the height of the caving zone maintained the height; the height of the WCFZ increased nonlinearly and unevenly with the advance of the working face after the working face passed through the borehole for $3 \mathrm{~m}$. In the end until the working face passed through the borehole for $30 \mathrm{~m}$, the height of the WCFZ turned to be basically stable: there were no longer changes with the advancing of the working face, and the maximum height of the WCFZ is predicted as $85.697 \mathrm{~m}$ at the floor height. 


\section{Conclusions}

Under the guidance of the new approach based on the optimized process proposed in this paper, the maximum height of the WCFZ was predicted successfully at one time under the condition of strong collapse of overburden, which avoided the expense of materials, time, and manpower. In the field monitoring based on BOTDR, several new inspiring results were obtained, as described as below.

(1) According to the geology and production conditions of the 150,313 working face, in order to field predict the height of the WCFZ with a thick coal seam and high strength of overburden collapse based on BOTDR, a new approach is proposed based on the optimized process: firstly, to estimate the height of the WCFZ ahead indoors; secondly, to design the borehole to be as close to the caving line of overburden as possible and the dip angle of the borehole to be a little bit smaller than the caving angle - the drilling height should be set according to the estimated height of the WCFZ; thirdly, to drill the borehole on the roof of the air-intake gateroad vertical to the strike of gateroad; fourthly, to install the selected optical cable via PVC pipes into the borehole; and the final step is to monitor the fiber strain using BOTDR with the special countermeasures for protecting the borehole and optical cables.

(2) The field experiment of fiber strain shows that the optical fiber strain in soft rock with lower elastic modulus presents a larger peak value of tensile strain, while the optical fiber in the rock with a higher elastic modulus and strength presents a platform curve of tensile strain.

(3) In the spatial sequence, the optical fiber strain characteristics in the caving zone are gradually increasing curves in the direction from the orifice to the bottom of the hole, finally reaching the peak strain value at the top of the caving zone. The strain of the optical fiber in the fracture zone is an irregular strain curve with a ladder-like reduction in the direction from the orifice to the bottom of the hole.

(4) In the time sequence, the value of optical fiber tensile strain increases gradually with the mining of the working face after the working face passed through the borehole for $3 \mathrm{~m}$, and then, it tends to be constant after the borehole passed through the borehole for $30 \mathrm{~m}$.

(5) Field test shows that the height of the caving zone is $27.058 \mathrm{~m}$ and the maximum height of the WCFZ is $85.697 \mathrm{~m}$ in the 150,313 working face. The height of the WCFZ increases nonlinearly with the working face advancing after the working face passed through the borehole for $3 \mathrm{~m}$, and it reaches the maximum value after the working face passed through the borehole for $30 \mathrm{~m}$.

(6) The results of field experiment, theoretical key stratum analysis, empirical formula calculation, and indoor model simulation experiment show a high degree of consistency, which shows that the new prediction process of BOTDR monitoring for the height of the WCFZ proposed in this paper is feasible and validated. The research and results of this paper are of significant reference to the prediction of the height of the WCFZ in coal mines under similar geology and production conditions.

Author Contributions: Conceptualization, T.H.; methodology, T.H.; software, S.B.; validation, S.B., Y.W. and Z.H.; formal analysis, T.H.; investigation, Z.L. and G.H.; resources, T.H.; data curation, T.H.; writing-original draft preparation, T.H.; writing-review and editing, Z.Z., Z.H.; visualization, T.H.; supervision, S.B., Y.W.; project administration, T.H.; funding acquisition, T.H., Z.H. All authors have read and agreed to the published version of the manuscript.

Funding: This research received no external funding.

Acknowledgments: Zhang Dan of Nanjing University and Zhang Dingding of Xi'an University of Science and Technology all gave guidance over the telephone many times. The field experiment was strongly supported by Wang Hongxian, Jia Lixiang, Li Xiangzhe etc of Nanzhi Co., Ltd., Suzhou, China. The field test was also guided by Liu Lei and Xu Guicheng from China Electronics Technology Instruments Co., Ltd., Qingdao, China. Technical personnel from Yinying Coal Mine have provided all-round help for our on-site testing. We would like to express our heartfelt thanks to them and all the comrades who have contributed to this project.

Conflicts of Interest: The authors declare no conflict of interest. 


\section{References}

1. Tang, B.; Cheng, H.; Tang, Y.; Zheng, T.; Yao, Z.; Wang, C.; Rong, C. Supporting Design Optimization of Tunnel Boring Machines-Excavated Coal Mine Roadways: A Case Study in Zhangji, China. Processes 2020, 8, 46. [CrossRef]

2. Wang, D.; Jiang, Y.; Sun, X.; Luan, H.; Zhang, H. Nonlinear Large Deformation Mechanism and Stability Control of Deep Soft Rock Roadway: A Case Study in China. Sustainability 2019, 11, 6243. [CrossRef]

3. Huang, D.; Li, W.; Chang, X.; Tan, Y. Key factors identification and risk assessment for the stability of deep surrounding rock in coal roadway. Int. J. Environ. Res. Public Health 2019, 16, 2802. [CrossRef] [PubMed]

4. Zhang, J.; Xu, K.; Reniers, G.; You, G. Statistical analysis the characteristics of extraordinarily severe coal mine accidents (ESCMAs) in China from 1950 to 2018. Process Saf. Environ. Prot. 2019. [CrossRef]

5. Skrzypkowski, K.; Korzeniowski, W.; Duc, T.N. Choice of powered roof support FAZOS-15/31-POz for Vang Danh hard coal. J. Pol. Miner. Eng. Soc. 2019, 21, 175-182. [CrossRef]

6. Minggao, Q.; Jialin, X. Behaviors of strata movement in coal mining. J. China Coal Soc. 2019, 44, 973-984.

7. Gongyu, H.; Tao, H.; Zixiang, L.; Bingbing, X.; Hailin, X.; Tianci, Z. Fiber optic strain characterization of "two zones" deformation of overburden mining based on BOFDA. J. Min. Saf. Eng. 2020, 37, 224-237. (In Chinese)

8. Liu, X.; Tan, Y.; Ning, J.; Tian, C.; Wang, J. The Height of Water-Conducting Fractured Zones in Longwall Mining of Shallow Coal Seams. Geotech. Geol. Eng. 2015, 33, 693-700. [CrossRef]

9. Ren, Z.; Wang, N. The Overburden Strata Caving Characteristics and Height Determination of Water Conducting Fracture Zone in Fully Mechanized Caving Mining of Extra Thick Coal Seam. Geotech. Geol. Eng. An Int. J. 2020, 38, 329-341. [CrossRef]

10. Majdi, A.; Hassani, F.P.; Nasiri, M.Y. Prediction of the height of destressed zone above the mined panel roof in longwall coal mining. Int. J. Coal Geol. 2012, 98, 62-72. [CrossRef]

11. Guo, W.; Zhao, G.; Lou, G.; Wang, S. A New Method of Predicting the Height of the Fractured Water-Conducting Zone Due to High-Intensity Longwall Coal Mining in China. Rock Mech. Rock Eng. 2019, 52, 2789-2802. [CrossRef]

12. Hu, T.; Hou, G.; Li, Z. The Field Monitoring Experiment of the Roof Strata Movement in Coal Mining Based on DFOS. Sensors 2020, 20, 1318. [CrossRef] [PubMed]

13. Zhang, Y.; Cao, S.; Gao, R.; Guo, S.; Lan, L. Prediction of the Heights of the Water-Conducting Fracture Zone in the Overlying Strata of Shortwall Block Mining Beneath Aquifers in Western China. Sustainability 2018, 10, 1636. [CrossRef]

14. Huang, W.P.; Li, C.; Zhang, L.W.; Yuan, Q.; Zheng, Y.S.; Liu, Y. In situ identification of water-permeable fractured zone in overlying composite strata. Int. J. Rock Mech. Min. Sci. 2018, 105, 85-97. [CrossRef]

15. Zhang, S.; Liu, Y. A Simple and Efficient Way to Detect the Mining Induced Water-conducting Fractured Zone in Overlying Strata. Energy Procedia 2012, 16, 70-75. [CrossRef]

16. Ning, J.; Wang, J.; Tan, Y.; Xu, Q. Mechanical mechanism of overlying strata breaking and development of fractured zone during close-distance coal seam group mining. Int. J. Min. Sci. Technol. 2020, 30, $207-215$. [CrossRef]

17. Cheng, G.; Ma, T.; Tang, C.; Liu, H.; Wang, S. A zoning model for coal mining-Induced strata movement based on microseismic monitoring. Int. J. Rock Mech. Min. Sci. 2017, 94, 123-138. [CrossRef]

18. Xiong, Z.Q.; Wang, C.; Zhang, N.C.; Tao, G.M. A field investigation for overlying strata behaviour study during protective seam longwall overmining. Arab. J. Geosci. 2015, 8, 7797-7809. [CrossRef]

19. Wei, J.; Wu, F.; Yin, H.; Guo, J.; Xie, D.; Xiao, L.; Zhi, H.; Lefticariu, L. Formation and Height of the Interconnected Fractures Zone after Extraction of Thick Coal Seams with Weak Overburden in Western China. Mine Water Environ. 2017, 36, 59-66. [CrossRef]

20. Hartog, A.H. An Introduction to Distributed Optical Fibre Sensors; CRC Press: Boca Raton, FL, USA, 2017.

21. Hoff, H. Using distributed fibre optic sensors for detecting fires and hot rollers on conveyor belts. In Proceedings of the 2nd International Conference for Fibre-Optic and Photonic Sensors for Industrial and Safety Applications (OFSIS), Brisbane, Australia, 8-10 January 2017; pp. 70-76.

22. Aminossadati, S.M.; Amanzadeh, M. Development of fibre-optic sensors for Australian mining industry. In Proceedings of the 2017 Conference on Lasers \& Electro-Optics Pacific Rim (CLEO-PR), Singapore, 31 July-4 August 2017; pp. 1-3. 
23. Liu, T.; Wei, Y.; Song, G.; Li, Y.; Wang, J.; Ning, Y.; Lu, Y. Advances of optical fiber sensors for coal mine safety monitoring applications. In Proceedings of the IEEE International Conference on Microwave and Photonics (ICMAP), Dhanbad, India, 13-15 December 2013; pp. 1-5.

24. Zhang, D.; Zhang, P.S.; Shi, B.; Wang, H.X.; Li, C.S. Monitoring and analysis of overburden deformation and failure using distributed fiber optic sensing. Chin. J. Geotech. Eng. 2015, 37, 952-957. (In Chinese)

25. Shaolin, L.; Dan, Z.; Pingsong, Z.; Jiacheng, W.; Bin, S. Deformation Monitoring of overburden based on distributed optical fiber. J. Eng. Geol. 2016, 24, 1118-1125. [CrossRef]

26. Piao, C.D.; Shi, B.; Wei, G.Q.; Yu, L.; Chen, E.Y. BOTDA distributed measurement and analysis of mining overburden separation. J. Min. Saf. Eng. 2015, 32, 376-381. (In Chinese)

27. Cheng, G.; Shi, B.; Zhu, H.; Zhang, C.; Wu, J. A field study on distributed fiber optic de-formation monitoring of overlying strata during coal mining. J Civ. Strut. Health Monit. 2015, 5, 553-562. [CrossRef]

28. Liu, Y.; Li, W.; He, J.; Liu, S.; Cai, L.; Cheng, G. Application of Brillouin optical time domain reflectometry to dynamic monitoring of overburden deformation and failure caused by underground mining. Int. J. Rock Mech. Min. Sci. 2018, 106, 133-143. [CrossRef]

29. Liu, Y.; Liu, Q.M.; Li, W.P.; Li, T.; He, J.H. Height of water-conducting fractured zone in coal mining in the soil-rock composite structure overburdens. Environ. Geol. 2019, 78, 242. [CrossRef]

30. Pawełczyk, M.; Fulara, S.; Sepe, M.; De Luca, A.; Bad Ora, M. Industrial gas turbine operating parameters monitoring and data-driven prediction. Eksploatacja i Niezawodnosc Maint. Reliab. 2020, 22, 391-399. [CrossRef]

31. Chudzik, A.; Warda, B. Fatigue life prediction of a radial cylindrical roller bearing subjected to a combined load using FEM. Eksploatacja i Niezawodnosc Maint. Reliab. 2020, 22, 212-220. [CrossRef]

32. Vališ, D.; Mazurkiewicz, D. Application of selected Levy processes for degradation modelling of long range mine belt using real-time data. Arch. Civ. Mech. Eng. 2018, 18, 1430-1440. [CrossRef]

33. Kozłowski, E.; Mazurkiewicz, D.; Kowalska, B.; Kowalski, D. Application of a multidimensional scaling method to identify the factors influencing on reliability of deep wells. In Proceedings of the International Conference on Intelligent Systems in Production Engineering and Maintenance, Wroclaw, Poland, 17-18 September 2018; Springer: Cham, Switzerland, 2018.

34. Sun, B.; Li, M.M.; Liao, B.P.; Yang, X.; Cao, Y.T.; Cui, B.F.; Feng, Q.; Ren, Y.; Yang, D.Z. Time-variant reliability modeling based on hybrid non-probability method. Arch. Appl. Mech. 2020, 90, 209-219. [CrossRef]

35. Naruse, H.; Komatsu, K.; Fujihashi, K.; Okutsu, M. Telecommunications tunnel monitoring system based on distributed optical fiber strain measurement. Int. Soc. Opt. Photonics 2005, 5855, 168-171.

36. Bao, X.; Chen, L. Recent Progress in Distributed Fiber Optic Sensors. Sensors 2012, 12, 8601-8639. [CrossRef] [PubMed]

37. Ding, Y.; Shi, B.; Zhang, D. Data processing in BOTDR distributed strain measurement based on pattern recognition. Opt. Int. J. Light Electr. Opt. 2010, 121, 2234-2239. [CrossRef]

38. Ohno, H.; Naruse, H.; Kihara, M.; Shimada, A. Industrial Applications of the BOTDR Optical Fiber Strain Sensor. Opt. Fiber Technol. Mater. Devices Syst. 2001, 7, 45-64. [CrossRef]

39. State Bureau of Coal Industry. Specification for Coal Pillar Retention and Coalmining in Buildings, Water Bodies, Railways and Main Wells and Alley; Coal Industry Press: Beijing, China, 2017.

40. Xu, J.L.; Zhu, W.B.; Wang, X.Z. New method to predict the height of fractured water-conducting zone by location of key strata. J. China Coal Soc. 2012, 37, 762-769.

41. Jinfeng, J.; Jialin, X. Structural characteristics of key strata and strata behavior of a fully mechanized longwall face with 7.0m height chocks. Int. J. Rock Mech. Min. Sci. 2013, 58, 46-54.

(C) 2020 by the authors. Licensee MDPI, Basel, Switzerland. This article is an open access article distributed under the terms and conditions of the Creative Commons Attribution (CC BY) license (http://creativecommons.org/licenses/by/4.0/). 